\title{
Validity and reliability of the German version of the 9-item European Heart Failure Self-care Behaviour Scale
}

Stefan Koeberich, Manuela Glattacker, Tiny Jaarsma, Christa Lohrmann and Theo Dassen

\section{Linköping University Post Print}

\section{Tweet}

N.B.: When citing this work, cite the original article.

Original Publication:

Stefan Koeberich, Manuela Glattacker, Tiny Jaarsma, Christa Lohrmann and Theo Dassen, Validity and reliability of the German version of the 9-item European Heart Failure Self-care Behaviour Scale, 2013, European Journal of Cardiovascular Nursing, (12), 2, 150-158. http://dx.doi.org/10.1177/1474515112438639

Copyright: Elsevier / SAGE Publications (UK and US) http://www.uk.sagepub.com/home.nav

Postprint available at: Linköping University Electronic Press http://urn.kb.se/resolve?urn=urn:nbn:se:liu:diva-93264 


\section{Validity and reliability of the German version of the 9-item European Heart}

\section{Failure Self-care Behaviour Scale}

Stefan Köberich ${ }^{1,5}$, Manuela Glattacker ${ }^{2}$, Tiny Jaarsma ${ }^{3}$, Christa Lohrmann ${ }^{4}$, Theo Dassen ${ }^{5}$

${ }^{1}$ Dept. of Cardiology/Angiology, University Freiburg - Medical Center, Hugstetter Str. 55, 79106 Freiburg, Germany

${ }^{2}$ Dept. of Quality Management and Social Medicine, University Freiburg - Medical Center, Engelbergerstr. 21, 79106 Freiburg, Germany

${ }^{3}$ Dept. of Social and Welfare Studies (HAV), Linköping University, 60174 Norrköping, Sweden

${ }^{4}$ Institute of Nursing Science, University Graz, Billrothgasse 6, 8010 Graz, Austria

${ }^{5}$ Dept. of Nursing Science, Charité - Universitätsmedizin Berlin, Augustenburger Platz 1, 13353 Berlin, Germany

\section{Corresponding author:}

Stefan Köberich

University Freiburg - Medical Center

Department of Cardiology/Angiology

Hugstetter Str. 55

79106 Freiburg

Germany

E-Mail: stefan.koeberich@uniklinik-freiburg.de

Phone/Fax: +49 76127037650 


\section{Abstract:}

Background:

The promotion of self-care in patients with heart failure (HF) is a promising strategy for maintaining health and preventing exacerbation of $\mathrm{HF}$ and a continuous need for health care services. To assess patient self-care, valid and reliable instruments are needed, but there is no psychometrically tested instrument for use in a German HF population.

Aim:

The aim of this study was to determine the validity and reliability of the German version of the 9-item European Heart Failure Self-care Behaviour Scale (G9-EHFScBS). Construct validity including factor analysis and discriminant validity, concurrent validity, test-retest reliability and internal consistency were analysed.

\section{Methods and results:}

The 9-item European Heart Failure Self-care Behaviour Scale was translated into German, and its validity and reliability were tested with 109 patients. The item-total correlation ranged from 0.09 to 0.63 . Internal consistency was fair, with a Cronbach's alpha of 0.71 (95\% Cl: $0.63-0.77)$. Test-retest reliability using an intra-class correlation coefficient showed substantial agreement for the entire scale (ICC: $0.69 ; 95 \% \mathrm{Cl}: 0.56-0.79)$. The G9-EHFScBS was able to distinguish patients with and without extra HF education at a statistically significant level ( $t=2.105 ; p=0.04)$. A factor analysis did not show the theoretical assumed dimensions of the scale. 


\section{Conclusion:}

The G9-EHFScBS is deemed a valid and reliable instrument to assess HF-specific self-care in a German HF population. 
Keywords:

Heart Failure; Self-care; European Heart Failure Self-care Behaviour Scale; Assessment; Validity; Reliability 


\section{Introduction}

\subsection{Background}

Heart failure (HF) is one of the most prevalent diseases in western industrialised countries. In Europe, approximately 2-3\% of the population suffer from HF, with expected increases in the incidence and prevalence of HF in the next decades $[1,2]$. Despite the advancements in medical treatment, overall hospital readmission rates of HF patients remain high. The treatment of HF patients accounts for up to $2 \%$ of total health care expenditures $[3,4]$. For example, in Germany, HF was the leading reason for hospital admission in 2006, with an annual cost of 2.9 billion Euros for all levels of treatment [5].

In addition to optimising medical therapy, improving patient self-care is regarded as a strategy for reducing the economic burden of HF [6]. Enhancing a patient's ability to follow lifestyle and medical recommendations and to recognise the symptoms and signs of worsening $\mathrm{HF}$ and adequately react to these signs (e.g., contacting health care providers) can lead to decreased rehospitalisation rates [6]. However, delays in care-seeking in cases of HF symptoms remain common [7-9].

Self-care education by health care providers is an excellent strategy to improve patient selfcare $[10,11]$. To evaluate the outcomes of self-care education, valid and reliable instruments measuring self-care in HF patients are needed. Only two instruments have undergone sufficient psychometric testing: the European Heart Failure Self-care Behaviour Scale (EHFScBS) and the Self-care Heart Failure Index (SCHFI) [12].

In preparation for a study about the effects of HF education on patient performance of selfcare measures, we decided to use the EHFScBS. Although a German version of the EHFScBS already exists, it has not been tested psychometrically. Therefore, the aim of this study was 
to evaluate the validity and reliability of the German version of the 9-item European Heart Failure Self-care Behaviour Scale (G9-EHFScBS).

\subsection{The European Heart Failure Self-care Behaviour Scale}

The first version of the EHFScBS was published by Jaarsma and colleagues in 2003 [13]. It was a self-administered questionnaire that contained 20 items on different aspects of HFrelated self-care. The responses were dichotomous (yes/no). The items could be conceptually divided into three dimensions, covering statements about compliance with the overall HF regime, actions to take in case of worsening HF and adapting activities to HF. The first psychometric testing, performed on 197 Dutch HF patients, showed only sufficient reliability, with Cronbach's alpha $<0.7$. The theoretically assumed dimensions could not be fully confirmed by a factor analysis. Some of the items loaded on more than one factor, which led to the decision to use only a sum score and to revise the scale.

After rerating the importance of every item, the number of items was reduced from 20 to 12. The scoring format was revised, and items could now be answered on a 5-point Likert scale, ranging from 1 (I completely agree) to 5 (I don't agree at all). The scale was psychometrically tested in 442 patients in three countries (the Netherlands, Sweden and Italy) [13]. Cronbach's alpha ranged from 0.69 to 0.93 , and a factor analysis confirmed only one of the assumed dimensions. The ability of the scale to discriminate between patients with and without extra HF education (discriminant validity) was tested and confirmed.

The EHFScBS was tested and revised again in 2009 [14]. A pooled convenience sample from six countries (the Netherlands, Sweden, the United Kingdom, Italy, Germany and Spain) was used to determine construct validity, convergent validity, discriminant validity and reliability. Content validity was confirmed by patients and researchers and through a review of existing 
HF guidelines. Confirmatory factor analysis (CFA) was used to test the assumed threedimensionality of the scale but was not able to demonstrate model fitting. A one-factor analysis showed insufficient results. Due to the results of the item-total correlation and the CFA, the number of items was reduced from 12 to 9 .

The 9-item version of the EHFScBS was moderately correlated with the revised Heart Failure Compliance Questionnaire but poorly correlated with the Minnesota Living with Heart Failure Questionnaire, a quality of life questionnaire. The reliability of the 9-item scale was 0.77 .

\subsection{Translation and modification of the 9-item EHFSCBS}

In preparation for this study, the 9-item EHFScBS [14] was translated into the German language again. This decision to re-translate the EHFScBS was made based on the author's belief that some of the translated items did not match the original meaning. For example, "fatigue" was translated into "Tagesmüdigkeit," which means, if back-translated, "daytime sleepiness". However, sleepiness is seen as a criterion for chronic fatigue syndrome or a disease in itself [15] even though it is often used as a synonym for fatigue [16].

After receiving permission from the authors, we performed a translation according to the model of Brislin [17]. The EHFScBS was translated into German by four German nurses who have excellent knowledge of the English language. The four translated scales were compared, and differences were discussed by the translators and one of the authors (S.K.). A conjoint version was then developed. This version was back-translated into English by three health care providers who are native English speakers. The back-translated versions were checked for any differences in meaning with the original version by a professional translator. No differences in meaning were detected. 
Every item was checked for consistency with the German HF guidelines [18] to ensure content validity. One difference was detected. Consequently, the item "If I gain $2 \mathrm{~kg}$ in 1 week..." was changed to "If I gain more than $2 \mathrm{~kg}$ in 3 days...". Additionally, even though the German HF guidelines no longer recommend salt restriction, this item was retained. Our experience in caring for HF patients suggests that dietary salt restriction is an important aspect of HF self-care. For example, salty foods could lead to an extensive feeling of thirst, with a consequent fluid intake in excess of recommended amounts. This possibility must be taken into account by the patient and should therefore be discussed within an education session about HF self-care behaviours.

After this modification, we performed a pre-test with 20 patients for comprehensibility. Patients were asked if they had any trouble understanding the items or completing the questionnaire. None of the patients indicated any difficulties.

\section{Methods}

\subsection{Design}

To evaluate the validity and reliability of the German version of the 9-item EHFScBS (G9EHFScBS), a cross-sectional survey was conducted between May 2010 and February 2011 at the Department of Cardiology of a university-affiliated hospital in southern Germany. Construct validity including factor analysis and discriminant validity, concurrent validity, testretest reliability and internal consistency was analysed.

\subsection{Study population}

Patients who were diagnosed with chronic HF and admitted to the department of cardiology or attended the HF outpatient clinic were screened for eligibility to participate in this study. 
Exclusion criteria were as follows: age $<18$, could not sufficiently read/understand the German language, diagnosed with HF for the first time, life expectancy $<3$ months as judged by the attending physician, hospital stay within the last 14 days and disorientation towards one of the following perspectives: time, person, situation or location.

While recommendations about an optimal sample size for factor analysis don't exist [19] we used a 10:1 ratio approach (i.e. 10 patients per variable) which is seen as a rather broad sample size calculation [20]. To ensure sufficient complete data sets, 165 patients were approached and 109 ultimately took part in this study.

\subsection{Procedure}

Eligible patients were asked to participate and received written information about the study aims and procedure. In-depth information was provided by the researcher. If the patient was willing to participate, a consent form was signed. The study protocol was approved by the local ethical committee, and the study conforms to the principles outlined in the Declaration of Helsinki [21].

Data collection was performed using self-administered questionnaires that were handed out to the patients during their hospital stays or during their visits to the outpatient clinic. Sociodemographic and disease-specific data were collected from the patients directly and by reviewing their medical records.

To determine test-retest reliability the G9-EHFScBS was sent out to the patients two weeks after discharge, with the request to fill out the questionnaire again and return it to the investigator by post. Participants who received an in-hospital education about self-care behaviours received the G9-EHFScBS twice after the education session ( 4 and 6 weeks after 
discharge). If the patients did not return the questionnaire after two weeks, an additional questionnaire with a reminder letter was sent out.

Although an optimal time interval to measure test-retest reliability is unknown, Streiner \& Norman [22, p. 182] suggest that using a time interval of 2 to 14 days is acceptable. We used a 14-day time interval under the assumption that self-care will remain largely the same within this time period. During these 14 days, patients received no extra education and were not receiving special support.

\section{Measurements}

To assess discriminant validity, each participant completed the Kansas City Cardiomyopathy Questionnaire (KCCQ), which measures health-related quality of life (QoL). As shown in previous studies, QoL and self-care in terms of performing self-care measures are not related constructs, even though there is a statistically significant relationship between QoL and patients' confidence in following self-care recommendations [23-26]. Our hypothesis was that Qol as measured by the KCCQ and self-care as measured by the G9-EHFScBS are not correlated.

The KCCQ is a reliable and valid instrument that measures a patient's quality of life; it consists of 6 domains $[27,28]$. The KCCQ has 23 items, each rated by a Likert scale with different ranges. The standardised total score ranges from 0-100, with a lower score indicating a lower quality of life.

To assess patients' self-care behaviours, the patients received the G9-EHFScBS. It contains of nine statements about HF specific self-care which has to be rated on a 5-point Likert-Scale. Only the poles of the Likert-Scale are labelled ("completely agree" and "I don't agree at all"). 
The sum score of the G9-EHFScBS ranged from 9 to 45 with lower scores indicating better self-care.

\section{Data Analysis}

The data were coded and entered into IBM SPSS Statistics, Version 19.

The data that were missing from the G9-EHFScBS were substituted according to the rule of the scale's developer. In detail, if fewer than 3 items of the total scale were missing, then every missing item was substituted with a 3 [13].

The missing values within a domain of the KCCQ were also substituted according to the developers' guidelines. They were assigned as the mean of the answered item within the specific domain [28].

To describe the patient characteristics, descriptive statistics were used. Nominal scaled variables are displayed as numbers and percentages. Interval scaled variables are displayed as the mean values and standard deviations if normally distributed; otherwise, they are displayed as medians and interquartile ranges.

Data of all single items of the G9-EHFScBS were handled as interval-scales. This was based on the argument that Likert-Scales could be considered as approximate interval-scaled if just the poles of the scale are labelled and these poles are the extremes of a continuum [29]. Internal consistency reliability was determined using Cronbach's alpha. The 95\% confidence interval of Cronbach's alpha was calculated using the formula provided by Streiner \& Norman [22, p.92-93]. According to Ponterotto \& Ruckdeschel's matrix for estimating the adequacy of internal consistency coefficients with research measures [30], a Cronbach's alpha of 0.70 is deemed fair, 0.75 is deemed moderate, 0.80 is deemed good, and 0.85 is deemed excellent for a scale of 7-11 items and a sample size between 100 and 300 . 
To describe the test-retest reliability of the G9-EHFScBS, an intra-class correlation coefficient (ICC) with a 95\% confidence interval was used. To determine the test-retest reliability, the ICC was used due to its sensitive detection of systematic error within the measured variables over time [31]. An ICC of 0.21-0.40 indicates fair agreement, $0.41-0.60$ indicates moderate agreement, $0.61-0.80$ indicates substantial agreement and $\geq 0.81$ indicates perfect agreement [32].

To determine the construct validity of the G9-EHFScBS, discriminant validity was assessed, and an explorative factor analysis was conducted using a principal component analysis with a varimax rotation. To determine the discriminant validity, the correlation between the G9EHFScBS and the sum score of the KCCQ was computed using Pearson's $r$.

Furthermore, concurrent validity was calculated. Concurrent validity is approved when a scale is able to distinguish between different groups of people, of which one group shows the measured construct, and the other does not. In this case, patients with and without an in-hospital education about HF were compared using the G9-EHFScBS. To determine significant differences, a $t$-test for independent groups was used.

\section{Results}

\subsection{Sample characteristics}

One hundred fifty-six patients were approached, of whom 32 (19.9\%) declined to participate, and 15 (9.6\%) were excluded according to the exclusion criteria and other reasons (figure 1). In total, the study population consisted of 109 patients.

\section{[figure 1]}


The characteristics of the 109 participants are summarised in table 1 . The patients were primarily men, married and had nine years of school education. Dilated cardiomyopathy and ischaemic heart disease were the most common reasons for HF. The median left ventricular ejection fraction (LVEF) was $25 \%$, and patients were predominantly classified as New York Heart Association (NYHA) classes II and III.

\section{[table 1]}

\subsection{Item analysis}

The response rate, mean and standard deviations of each single item and of the total score are presented in table 2 . The distribution of the item answers indicated that most were biased toward the answer "I completely agree", which led to a positively skewed distribution. The exceptions were items 6 and 7, which were nearly uniformly distributed.

\section{[table 2]}

\subsection{Internal consistency}

Cronbach's alpha for the total scale was 0.71 (95\% Cl: 0.63-0.77) and would increase if item 8 or item 9 were deleted ( 0.72 and 0.73 , respectively). The item-total correlation ranged from 0.09-0.63, with two items (items 8 and 9) weakly correlated $(r<0.2)$ with the total scale.

\subsection{Test-retest reliability}

To determine the test-retest reliability, 87 patient datasets were analysed. Of these 87 patients, 74 (85.1\%) returned the questionnaire within 14 days. Test-retest reliability 
showed substantial agreement for the total scale (ICC: $0.69 ; 95 \% \mathrm{Cl}: 0.56-0.79$ ). ICC on an item level ranged from $0.40-0.87$, indicating fair to perfect agreement (Table 3).

\section{[table 3]}

\subsection{Discriminant validity}

As hypothesised, the correlation between the modified German version of the G9-EHFScBS and the KCCQ was weak and was not statistically significant (Pearson's $r=0.096 ; p=0.32$ ), indicating that these instruments measure different constructs.

\subsection{Factor analysis}

Principal component analyses with varimax rotation revealed that the three factors of the scale account for $62.6 \%$ of the variance, with the first factor accounting for $34 \%$ and the first two factors for $50 \%$ of the variance.

An in-depth analysis of the item loadings on the three factors showed that items 2, 3, 4 and 6 were loading on factor one, with factor loadings of 0.765 to 0.889 , which comprises all items of the theme "Asking for help". The Cronbach`s alpha of this subscale was 0.86 . Items 5, 7 and 9 loaded on factor 2 (alpha: 0.47), and items 1 and 8 loaded on factor 3 (alpha: 0.19), even though these items reflect a similar theme ("complying with the regime") (table 4). These results suggest that only one subscale can be distinguished.

\section{[table 4]}

\subsection{Concurrent validity}


Concurrent validity was determined by comparing the means of the G9-EHFScBS sum scores of the patients who received an HF education and the patients who did not.

Overall, 19 patients (18.3\%) took part in an education session regarding HF and HF-related self-care behaviours. For these patients, the sum score of the G9-EHFScBS were lower than for those with no education $(p=0.038)$ (Table 5). Patients with and without an in-hospital education did not differ in their basic characteristics with the exception of LVEF. The patients who took part in an education session showed a significantly lower LVEF than those with no education (LVEF: $23.2 \%$ vs. $28.9 \%$; $p=0.009$ ).

\section{[Table 5]}

\section{Discussion}

The aim of this study was to determine the construct and concurrent validity, internal consistency and test-retest reliability of the G9-EHFScBS. Overall, the data analysis showed that the G9-EHFScBS is a valid and reliable instrument to measure HF-related self-care. However, validity could only be approved with regard to discriminant and concurrent validity, while the results of the factor analysis could not show the theoretical assumed dimensions of the scale.

The answers to the items were mostly biased toward scores of 1 or 2, leading to a positively skewed distribution and indicating the study population's adherence to recommended selfcare behaviours. This finding is in line with the results of previously conducted validity studies of the EHFScBS $[14,33,34]$. Because of the skewed distribution, changes in self-care behaviours, such as those due to self-care education, might be difficult to measure. 
Furthermore, the biased item answers influenced some aspects of reliability. Cronbach's alpha of the G9-EHFSCB for this patient dataset was 0.71 , indicating only fair internal consistency, which is lower than in the original version of the 9-item EHFScBS (0.8) [14]. One possible explanation for the lower alpha value is that our sample is more homogeneous regarding self-care activities, which can be deduced from the skewed distribution of their answers. As outlined by Streiner, "the more heterogeneous the sample, then the larger the variance of the total scores and the higher the reliability" [35, p. 101]. Therefore, Cronbach's alpha might be higher in a different HF population than in the patients included in this study. It can be surmised that some items (e.g., items 8 and 9) not only reflect HF-specific self-care measures, but also reflect global aspects of self-care and, as a consequence, contribute to the lower internal consistency. This assumption is underlined by the fact that the item-total correlation for these items was low and partly below the required correlation of $r<0.2$ (Item 8: 0.13; Item 9: 0.09). Deleting these items might be appropriate to enhance the internal consistency reliability of the scale, but their deletion would debase the content validity. However, to cover all of the important aspects of HF self-care, the items with low item-total correlation were retained. These issues should be considered in further scale development. The test-retest reliability using ICC showed substantial agreement for the entire scale. On an item level, the agreement ranged from fair to perfect. Items with only a fair to moderate agreement showed also reduced test-retest reliability in other studies. In a study by Shuldham and colleagues [36], the responses to items 4,5 and 6 at baseline and after 2 weeks differed the most, but the differences were not statistically significant. Kato et al. [33], testing the Japanese version of the 12-item EHFScBS, found that in addition to items 2 and 3 of the 9-item version, item 6 also showed only moderate agreement, as seen in our study. They stated that this finding might be because these items reflect self-care behaviours 
in terms of contacting health care staff. In addition, most of the study participants had only mild HF, with little experience of HF exacerbation.

This argument could be partly applied to our results, in which most patients were graded as NYHA II. Unfortunately, this approach does not explain why the test-retest reliability of item 5 showed only fair agreement. An improvement in test-retest reliability might be possible if one takes into account the fact that patients don't experience any sign or symptoms stated in the scale. For example, the SCHFI [37] does not calculate a self-care management score if patients have not experienced shortness of breath or ankle swelling in the past months. This approach could also be applied to the G9-EHFScBS.

Thirteen patients (14.9\%) did not return the questionnaire at the second measurement time within a 14-day period. Even though there is no evidence that a time interval of more than 14 days decreases the test-retest reliability of this scale, it is possible that self-care behaviour has changed within this time and that these changes have an influence on the test-retest reliability of the scale or of specific items of the G9-EHFScBS.

To evaluate the reasons for the fair and moderate test-retest reliability, further investigation is needed.

The G9-EHFScBS was able to distinguish between patients who received an education about HF-specific self-care measures and those who did not. However, it must be taken into account that those receiving an education about self-care behaviours showed a significantly lower LVEF than those who received no extra education. In one study, LVEF is described as a self-care behaviour-influencing factor [26]. Seto et al. found that the lower the LVEF, the better self-care is performed. They concluded that this finding might be due to a greater need for patients with reduced LVEF to take care of themselves or that health care providers pay more attention to those patients. Because the influence of LVEF on HF-specific self-care 
behaviours is not sufficiently clear, further studies should be performed to determine the relationship between reduced LVEF and self-care.

As expected, QoL as measured with the KCCQ was not correlated with the G9-EHFSCBS, indicating that these two instrument measures different constructs, which is in line with previous studies $[14,36]$.

A principal component analysis with a varimax rotation revealed that three factors lie within the scale, which did not confirm the underlying hypothesis of a two-factor model. Interestingly, factor one could be conceptualised as the subscale "Asking for help", in line with the theoretical conception of the scale. However, the two other factors could not be distinguished conceptually. Theoretically, items 1, 5, 7, 8 and 9 should be summarised as "compliance with the regime", but this summary was not confirmed by our analysis. The ambiguous results of our factor analysis are in line with other studies analysing the internal structure of the EHFScBS. Shuldham et al. [36] identified a four-factor model for the 12-item EHFScBS, although only three factors can be distinguished by theory. Using a confirmatory factor analysis approach, Kato et al. [33] and Yu et al. [34] were not able to confirm the hypothetical underlying model. Additionally, Jaarsma and colleagues [14] were not able to demonstrate model fitting in the revised 9-item scale. As a consequence, the sum scores of the G9-EHFScBs and the score of the subscale "Asking for help" should be used.

In conclusion, the G9-EHFScBS is deemed a reliable and valid instrument to assess self-care in HF patients. It might help to tailor HF education sessions and to determine the effects of such interventions on HF patients' behaviours.

\section{Acknowledgements}


We would like to thank Rita Dunzweiler, secretary of the heart failure outpatient clinic, for recruiting patients for this study. 


\section{References}

[1] Dickstein K, Cohen-Solal A, Filippatos G, McMurray JJ, Ponikowski P, Poole-Wilson PA, Stromberg A, van Veldhuisen DJ, Atar D, Hoes AW, Keren A, Mebazaa A, Nieminen M, Priori SG, Swedberg K. ESC guidelines for the diagnosis and treatment of acute and chronic heart failure 2008: the Task Force for the diagnosis and treatment of acute and chronic heart failure 2008 of the European Society of Cardiology. Developed in collaboration with the Heart Failure Association of the ESC (HFA) and endorsed by the European Society of Intensive Care Medicine (ESICM). Eur J Heart Fail 2008;10(10):933-89

[2] Hense H-W. [Epidemiology of heart failure]. Med Welt 2004;55(11/12):374-9

[3] Berry C, Murdoch DR, McMurray JJ. Economics of chronic heart failure. Eur J Heart Fail $2001 ; 3(3): 283-91$

[4] Lee WC, Chavez YE, Baker T, Luce BR. Economic burden of heart failure: a summary of recent literature. Heart Lung 2004;33(6):362-71

[5] Neumann T, Biermann J, Erbel R, Neumann A, Wasem J, Ertl G, Dietz R. Heart failure: the commonest reason for hospital admission in Germany: medical and economic perspectives. Dtsch Arztebl Int 2009;106(16):269-75

[6] Jovicic A, Holroyd-Leduc JM, Straus SE. Effects of self-management intervention on health outcomes of patients with heart failure: a systematic review of randomized controlled trials. BMC Cardiovasc Disord 2006;6(43 
[7] Evangelista LS, Dracup K, Doering LV. Treatment-seeking delays in heart failure patients. J Heart Lung Transplant 2000;19(10):932-8

[8] Jurgens CY. Somatic awareness, uncertainty, and delay in care-seeking in acute heart failure. Res Nurs Health 2006;29(2):74-86

[9] Nieuwenhuis MM, Jaarsma T, van Veldhuisen DJ, van der Wal MH. Factors associated with patient delay in seeking care after worsening symptoms in heart failure patients. J Card Fail 2011;17(8):657-63

[10] Jaarsma T, Halfens R, Huijer Abu-Saad H, Dracup K, Gorgels T, van Ree J, Stappers J. Effects of education and support on self-care and resource utilization in patients with heart failure. Eur Heart J 1999;20(9):673-82

[11] Koelling TM, Johnson ML, Cody RJ, Aaronson KD. Discharge education improves clinical outcomes in patients with chronic heart failure. Circulation 2005;111(2):179-85

[12] Cameron J, Worrall-Carter L, Driscoll A, Stewart S. Measuring self-care in chronic heart failure: a review of the psychometric properties of clinical instruments. J Cardiovasc Nurs 2009;24(6):E10-22

[13] Jaarsma T, Stromberg A, Martensson J, Dracup K. Development and testing of the European Heart Failure Self-Care Behaviour Scale. Eur J Heart Fail 2003;5(3):363-70 
[14] Jaarsma T, Arestedt KF, Martensson J, Dracup K, Stromberg A. The European Heart Failure Self-care Behaviour scale revised into a nine-item scale (EHFScB-9): a reliable and valid international instrument. Eur J Heart Fail 2009;11(1):99-105

[15] Avellaneda Fernandez A, Perez Martin A, Izquierdo Martinez M, Arruti Bustillo M, Barbado Hernandez FJ, de la Cruz Labrado J, Diaz-Delgado Penas R, Gutierrez Rivas E, Palacin Delgado C, Rivera Redondo J, Ramon Gimenez JR. Chronic fatigue syndrome: aetiology, diagnosis and treatment. BMC Psychiatry 2009;9 Suppl 1(S1

[16] Wessely S. Chronic fatigue: symptom and syndrome. Ann Intern Med 2001;134(9 Pt 2):838-43

[17] Brislin R. The wording and translation of research instruments. In: W Lonner, Berry J. Field methods in cross-cultural research. Beverly Hills, Newbury Park, London, New Delhi: Sage Publications, 1986: 137-64

[18] Bundesärztekammer (BÄK), Kassenärztliche Bundesvereinigung (KBV), Arbeitsgemeinschaft der Wissenschaftlichen Medizinischen Fachgesellschaften (AWMF). Nationale VersorgungsLeitlinie Chronische Herzinsuffizienz - Langfassung. Version 1.1. [cited: 01.07.2010] Available from http://www.versorgungsleitlinien.de/themen/herzinsuffizienz

[19] MacCallum RC, Widaman K, Zhang S, Hong S. Sample size in factor analysis. Psychological Methods 1999;4(1):84-99 
[20] Bühner M. Einführung in die Test- und Fragebogenkonstruktion, 3. aktualisierte und erweiterte Auflage. München: Pearson Studium, 2010

[21] Rickham PP. Human Experimentation. Code of Ethics of the World Medical Association. Declaration of Helsinki. Br Med J 1964;2(5402):177

[22] Streiner DL, Norman GR. Health Measurement Scales: A Practical Guide to Their Developement and Use, 4th Revised. Oxford: Oxfrod University Press, 2008

[23] Buck HG, Lee CS, Moser DK, Albert NM, Lennie T, Bentley B, Worrall-Carter L, Riegel B. Relationship Between Self-care and Health-Related Quality of Life in Older Adults With Moderate to Advanced Heart Failure. J Cardiovasc Nurs 2011;in press): doi: 10.1097/JCN.0b013e3182106299

[24] Holst M, Willenheimer R, Martensson J, Lindholm M, Stromberg A. Telephone follow-up of self-care behaviour after a single session education of patients with heart failure in primary health care. Eur J Cardiovasc Nurs 2007;6(2):153-9

[25] Macabasco-O'Connell A, Dewalt DA, Broucksou KA, Hawk V, Baker DW, Schillinger D, Ruo B, Bibbins-Domingo K, Holmes GM, Erman B, Weinberger M, Pignone M. Relationship Between Literacy, Knowledge, Self-Care Behaviors, and Heart Failure-Related Quality of Life Among Patients With Heart Failure. J Gen Intern Med 2011;26(9):979-86 
[26] Seto E, Leonard KJ, Cafazzo JA, Masino C, Barnsley J, Ross HJ. Self-care and Quality of Life of Heart Failure Patients at a Multidisciplinary Heart Function Clinic. J Cardiovasc Nurs $2011 ; 26(5): 377-85$

[27] Faller H, Steinbuchel T, Schowalter M, Spertus JA, Stork S, Angermann CE. [The Kansas City Cardiomyopathy Questionnaire (KCCQ) -- a new disease-specific quality of life measure for patients with chronic heart failure]. Psychother Psychosom Med Psychol 2005;55(34):200-8

[28] Green CP, Porter CB, Bresnahan DR, Spertus JA. Development and evaluation of the Kansas City Cardiomyopathy Questionnaire: a new health status measure for heart failure. J Am Coll Cardiol 2000;35(5):1245-55

[29] Wirtz M, Caspar F. Beurteilerübereinstimmung und Beurteilerreliabilität, Göttingen, Bern, Toronto, Seattle: Hogrefe, 2002

[30] Ponterotto JG, Ruckdeschel DE. An overview of coefficient alpha and a reliability matrix for estimating adequacy of internal consistency coefficients with psychological research measures. Percept Mot Skills 2007;105(3 Pt 1):997-1014

[31] Yen M, Lo LH. Examining test-retest reliability: an intra-class correlation approach. Nurs Res 2002;51(1):59-62 
[32] Andresen EM, Malmstrom TK, Miller DK, Miller JP, Wolinsky FD. Retest reliability of selfreported function, self-care, and disease history. Med Care 2005;43(1):93-7

[33] Kato N, Ito N, Kinugawa K, Kazuma K. Validity and reliability of the Japanese version of the European Heart Failure Self-Care Behavior Scale. Eur J Cardiovasc Nurs 2008;7(4):284-9

[34] Yu DS, Lee DT, Thompson DR, Jaarsma T, Woo J, Leung EM. Psychometric properties of the Chinese version of the European Heart Failure Self-care Behaviour Scale. Int J Nurs Stud $2011 ; 48(4): 458-67$

[35] Streiner DL. Starting at the beginning: an introduction to coefficient alpha and internal consistency. J Pers Assess 2003;80(1):99-103

[36] Shuldham C, Theaker C, Jaarsma T, Cowie MR. Evaluation of the European Heart Failure Self-care Behaviour Scale in a United Kingdom population. J Adv Nurs 2007;60(1):87-95

[37] Riegel B, Lee CS, Dickson VV, Carlson B. An update on the self-care of heart failure index. J Cardiovasc Nurs 2009;24(6):485-97 


\section{Tables}

\begin{tabular}{|c|c|}
\hline Subject ( $n=109)$ & $\mathrm{n}(\%)$ \\
\hline \multicolumn{2}{|l|}{ Gender } \\
\hline Female & $32(29.4)$ \\
\hline Age (years) & $62.5( \pm 11.9)^{\#}$ \\
\hline \multicolumn{2}{|l|}{ Marital status ( $n=106)$} \\
\hline Single/Not married & $11(10.1)$ \\
\hline Married & $71(65.1)$ \\
\hline Widowed & $10(9.2)$ \\
\hline Divorced & $14(12.8)$ \\
\hline \multicolumn{2}{|l|}{ Living situation $(n=106)$} \\
\hline Living with someone & $83(76.1)$ \\
\hline Living alone & $23(21.1)$ \\
\hline \multicolumn{2}{|l|}{ Educational level ( $n=106)$} \\
\hline$\leq 9$ years & $57(52.3)$ \\
\hline 10 years & $29(26.6)$ \\
\hline 13 years & $8(7.3)$ \\
\hline 13 years + University degree & $11(10.1)$ \\
\hline \multicolumn{2}{|l|}{ Aetiology of heart failure $(n=108)$} \\
\hline Dilated cardiomyopathy & $48(44.0)$ \\
\hline Ischaemic heart disease & $50(45.9)$ \\
\hline Valvular disease & $4(3.7)$ \\
\hline Hypertrophic cardiomyopathy & $1(0.9)$ \\
\hline Others & $7(6.4)$ \\
\hline \multicolumn{2}{|l|}{ Medication $(n=108)$} \\
\hline Diuretics & $96(88.1)$ \\
\hline ACEI/ARB & $94(86.2)$ \\
\hline Beta blocker & $100(91.7)$ \\
\hline \multicolumn{2}{|l|}{ NYHA ( $n=105)$} \\
\hline NYHA I & $6(5.5)$ \\
\hline NYHA II & $56(51.4)$ \\
\hline NYHA III & $40(36.7)$ \\
\hline NYHA IV & $3(2.8)$ \\
\hline Left ventricular ejection fraction (\%) & $25(20-35)^{*}$ \\
\hline Body-mass index $\left(\mathrm{kg} / \mathrm{m}^{2}\right)(\mathrm{n}=107)$ & $27.3(24.2-30.8)^{*}$ \\
\hline \multicolumn{2}{|l|}{ Table 1: Subject characteristics } \\
\hline \multicolumn{2}{|c|}{$\begin{array}{l}\text { Abbr.: NYHA = New York Heart Association; ACE-Inhibitor = Angiotensin-Converting-Enzyme-Inhibitor; ARB = Angiotensin Receptor Blocker } \\
\text { \#Mean (Standard deviation) } \\
\text { * Median (Interquartile range) }\end{array}$} \\
\hline
\end{tabular}




\begin{tabular}{|c|c|c|c|c|c|c|c|}
\hline Item \# & Item description & Mean $( \pm S D)$ & 1 & 2 & 3 & 4 & 5 \\
\hline 1 & I weigh myself daily & $2.35( \pm 1,40)$ & $47(43.1 \%)$ & $12(11.0 \%)$ & $26(23.9 \%)$ & $13(11.9 \%)$ & $11(10.1 \%)$ \\
\hline 2 & If my shortness of breath increases, I contact my doctor or nurse & $2.00( \pm 1.28)$ & $56(51.4 \%)$ & $21(19.3 \%)$ & $17(15.6 \%)$ & $6(5.5 \%)$ & $9(8.3 \%)$ \\
\hline 3 & If my feet/legs become more swollen than usual, I contact my doctor or nurse & $2.21( \pm 1.42)$ & $49(45.0 \%)$ & $25(22.9 \%)$ & $11(10.1 \%)$ & $11(10.1 \%)$ & $13(11.9 \%)$ \\
\hline 4 & If I gain $2 \mathrm{~kg}$ in 3 days, I contact my doctor or nurse & $2.61( \pm 1.60)$ & $44(40.4 \%)$ & $12(11.0 \%)$ & $19(17.4 \%)$ & $10(9.2 \%)$ & $24(22.0 \%)$ \\
\hline 5 & I limit the amount of fluids I drink (not more than $1 \frac{1}{2}-2 \mathrm{~L} /$ day) & $2.03( \pm 1.27)$ & $52(47.7 \%)$ & $28(25.7 \%)$ & $11(10.1 \%)$ & $10(9.2 \%)$ & $8(7.3 \%)$ \\
\hline 6 & If I experience increased fatigue, I contact my doctor or nurse & $2.65( \pm 1.47)$ & $32(29.4 \%)$ & $26(23.9 \%)$ & $19(17.4 \%)$ & $12(11.0 \%)$ & $20(18.3 \%)$ \\
\hline 7 & I eat a low-salt diet & $2.90( \pm 1.35)$ & $20(18.3 \%)$ & $24(22.0 \%)$ & $33(30.3 \%)$ & $11(10.1 \%)$ & $21(19.3 \%)$ \\
\hline 8 & I take my medication as prescribed & $1.15( \pm 0.64)$ & $101(92.7 \%)$ & $5(4.6 \%)$ & $0(0 \%)$ & $1(0.9 \%)$ & $2(1.8 \%)$ \\
\hline 9 & I exercise regularly & $1.96( \pm 1.14)$ & $54(49.5 \%)$ & $19(17.4)$ & $26(23.9 \%)$ & $6(5.5 \%)$ & $4(3.7 \%)$ \\
\hline & Total score of G9-EHFScBS & $19.9( \pm 6.48)$ & & & & & \\
\hline
\end{tabular}




\begin{tabular}{r|l|r|c} 
Item \# & Item description & ICC & $95 \% \mathrm{Cl}$ \\
\hline 1 & I weigh myself daily & 0.76 & $0.65-0.83^{*}$ \\
2 & If my shortness of breath increases, I contact my doctor or nurse & 0.61 & $0.45-0.72^{*}$ \\
3 & If my feet/legs become more swollen than usual, I contact my doctor or & 0.61 & $0.46-0.73^{*}$ \\
& nurse & & \\
4 & If I gain 2 kg in 3 days, I contact my doctor or nurse & 0.44 & $0.26-0.60^{*}$ \\
5 & I limit the amount of fluids I drink (not more than 11/2-2 L/day) & 0.40 & $0.20-0.56^{*}$ \\
6 & If I experience increased fatigue, I contact my doctor or nurse & 0.47 & $0.29-0.62^{*}$ \\
7 & I eat a low-salt diet & 0.77 & $0.66-0.84^{*}$ \\
8 & I take my medication as prescribed & 0.87 & $0.81-0.91^{*}$ \\
9 & I exercise regularly & 0.72 & $0.60-0.81^{*}$
\end{tabular}

Table 3: Test-retest reliability of the G9-EHFSCBS $(n=87) ;{ }^{*} p<0.001$ 


\begin{tabular}{l|r|r|r} 
& \multicolumn{3}{c}{ Component } \\
\cline { 2 - 4 } I weigh myself daily & \multicolumn{1}{c}{1} & \multicolumn{1}{c}{2} & 3 \\
If my shortness of breath increases, I contact my doctor or nurse & 0.333 & -0.056 & 0.611 \\
If my feet/legs become more swollen than usual, I contact my doctor or nurse & 0.889 & -0.073 & 0.078 \\
If I gain 2 kg in 3 days, I contact my doctor or nurse & 0.765 & 0.131 & 0.203 \\
I limit the amount of fluid I drink (not more than 11/2-2 L/day) & 0.096 & 0.648 & 0.205 \\
If I experience increased fatigue, I contact my doctor or nurse & 0.852 & 0.100 & 0.034 \\
I eat a low-salt diet & 0.054 & 0.706 & 0.156 \\
I take my medication as prescribed & -0.088 & 0.270 & 0.750 \\
I exercise regularly & 0.030 & 0.696 & -0.423
\end{tabular}

Table 4: Component matrix (Principal component analysis with varimax rotation) 


\begin{tabular}{l|l|l|l|l} 
Education & $\mathrm{n}=$ & $\begin{array}{l}\text { G9-EHFScBS } \\
\text { Mean (SD) }\end{array}$ & T-test & $\mathrm{p}$ \\
\hline Yes & 19 & $\begin{array}{l}16.7( \pm 6.5) \\
\text { No }\end{array}$ & $\mathrm{t}=2.105$ & 0.038 \\
\hline
\end{tabular}

Table 5: Sum score G9-EHFScBS of educated vs. non-educated patients 